\title{
Interleukin-10 Inhibits Proinflammatory Chemokine Release by Neutrophils of the Newborn without Suppression of Nuclear Factor- $\kappa B$
}

\author{
JOHNY TRYZMEL, VERONIKA MISKOLCI, SUSANA CASTRO-ALCARAZ, \\ IVANA VANCUROVA, AND DENNIS DAVIDSON
}

Division of Neonatal-Perinatal Medicine, Schneider Children's Hospital, Long Island Jewish Medical

Center, the Long Island Campus for the Albert Einstein College of Medicine, New Hyde Park, New York

11040, U.S.A.

\begin{abstract}
An increase in polymorphonuclear leukocytes (PMNs) and proinflammatory chemokines, such as IL-8 and macrophage inflammatory protein- $1 \alpha$ (MIP), are found in the airways during early stages of bronchopulmonary dysplasia. We determined whether IL-10 produces a dose-related inhibition of proinflammatory chemokine release from stimulated neutrophils of the newborn and whether the mechanism involves the pivotal transcription factor, nuclear factor $-\kappa \mathrm{B}$. PMNs isolated from the cord blood of healthy newborns were stimulated submaximally with either lipopolysaccharide $(n=5)$ or tumor necrosis factor $(n=$ 4), with and without IL-10 (0.01-1000 ng/mL). IL-8 and MIP release were measured in cell culture supernatants at $18 \mathrm{~h}$. The presence or absence of nuclear factor- $\kappa \mathrm{B}$ activity and inhibitor$\kappa \mathrm{B} \alpha$ degradation was measured at $30 \mathrm{~min}$ and $3 \mathrm{~h}$ after PMN stimulation began. During lipopolysaccharide stimulation, IL-10 significantly reduced IL-8 levels from $50 \pm 16 \mathrm{ng} / \mathrm{mL}$ to $7 \pm 3$ $\mathrm{ng} / \mathrm{mL}$, and MIP levels from $14 \pm 5$ to $0.7 \pm 0.1 \mathrm{ng} / \mathrm{mL}$ (mean \pm SEM, $p<0.01$ ). IL-10 produced an insignificant reduction in IL-8 and MIP levels after stimulation of PMNs with tumor necrosis factor. IL-10 did not inhibit nuclear factor- $\kappa \mathrm{B}$ activation and inhibitor $-\kappa \mathrm{B} \alpha$ degradation in PMNs stimulated with tumor
\end{abstract}

\section{ABSTRACT}

necrosis factor or lipopolysaccharide for $30 \mathrm{~min}$. After PMN stimulation for $3 \mathrm{~h}$, inhibitor- $\kappa \mathrm{B} \alpha$ cytoplasmic levels were restored; however, they were unaffected by IL-10. We conclude that IL-10 is a potent inhibitor of lipopolysaccharide-stimulated release of IL- 8 and MIP from neutrophils of the newborn via a mechanism not involving nuclear factor- $\kappa \mathrm{B}$ activity. Further work is needed to determine whether exogenous IL-10 may be useful for suppressing inflammation in bronchopulmonary dysplasia. (Pediatr Res 54: 382-386, 2003)

$\quad$ Abbreviations
MIP, macrophage inflammatory protein- $1 \alpha$
TNF, tumor necrosis factor- $\alpha$
NF- $\alpha \mathbf{B}$, nuclear factor- $\kappa \mathrm{B}$
I- $\boldsymbol{\kappa} \mathbf{B} \boldsymbol{\alpha}$, inhibitory factor- $\boldsymbol{\kappa} \mathrm{B} \alpha$
LPS, lipopolysaccharide
PMN, polymorphonuclear leukocyte
CLD, chronic lung disease
BPD, bronchopulmonary dysplasia
EMSA, electrophoretic mobility shift assay

During the first few days of acute lung injury in the newborn, the predominant inflammatory cell recruited into the lung is the PMN, and the level of influx of these cells is predictive of $\operatorname{BPD}(1,2)$. PMNs are now known to be more than effector cells; they have the ability to amplify recruitment of PMNs and inflammation by the release of chemokines $(3,4)$. IL-8 and MIP are two potent chemokines, released by PMNs, that have

Received January 30, 2003; accepted April 23, 2003.

Correspondence: Dennis Davidson, M.D., Division of Neonatal-Perinatal Medicine, Schneider Children's Hospital, 269-01 76th Avenue, New Hyde Park, NY 11040, U.S.A.; e-mail: davidson@lij.edu

Funded in part by Forest Pharmaceuticals, Inc. (Grant Program for Fellows).

DOI: 10.1203/01.PDR.0000077471.36217.6E been detected in the airway fluid of newborns early in the development of $\operatorname{BPD}(5,6)$. The release of these chemokines is thought to be under the control of a pivotal proinflammatory transcription factor, NF- $\kappa \mathrm{B}$ (7). In the PMN, the unique control of activity and cellular location of NF- $\kappa \mathrm{B}$ is now being studied with great intensity (8). In our previous work, using PMNs of the newborn, dexamethasone was shown to inhibit NF- $\kappa \mathrm{B}$ activity and the release of these chemokines (9).

There is an urgent need to find safe and effective antiinflammatory therapy, as an alternative to past dexamethasone practices, for the treatment of BPD (10). IL-10 is a potent antiinflammatory cytokine that is produced by macrophages and possibly neutrophils and other lung cells (11). There is evi- 
dence that IL-10 can suppress many proinflammatory functions of the PMN, but IL-10 may not be produced in sufficient quantity in the newborn to suppress inflammation (12). Therapy with exogenous recombinant IL-10 has been started experimentally in certain inflammatory diseases of the adult but not yet for the newborn (13). Therefore, the specific aims of the present study were to determine whether IL-10 is a potent inhibitor of chemokine release from neutrophils of the newborn and whether its mechanism of action was caused by inhibition of NF- $\kappa \mathrm{B}$ activity.

\section{METHODS}

\section{Subjects}

Cord blood (approximately $30 \mathrm{~mL}$ ) was obtained from the placenta immediately after elective, cesarean section delivery of 11 term infants, without exposure to general anesthesia. Blood was collected in heparinized, preservative-free tubes for transport to the laboratory, followed by immediate PMN isolation. The study was approved by the Human Subjects Review Committee of the North Shore-Long Island Jewish Health Care System.

\section{PMN Isolation and Culture Protocol}

PMNs were isolated under endotoxin-free conditions using Ficoll-Paque and dextran (Pharmacia, Piscataway, NJ, U.S.A.) centrifugation and sedimentation, respectively, followed by hypotonic lysis of the residual erythrocytes as described previously (14). The isolated cells contained more than 98\% PMNs, and the cells were 99\% viable as determined by trypanblue exclusion. Purified cells were resuspended in RPMI 1640 supplemented with 10\% FCS (Life Technologies, Grand Island, NY, U.S.A.) to obtain a final concentration of $5 \times 10^{6}$ cells $/ \mathrm{mL}$ at $37^{\circ} \mathrm{C}$.

Cells were exposed to serial doses of purified, recombinant IL-10 (R\&D Systems, Minneapolis, MN, U.S.A.) and incubated at $37^{\circ} \mathrm{C}$ for $1 \mathrm{~h}$ before stimulation with LPS (Sigma Chemical Co., St. Louis, MO, U.S.A.) or recombinant TNF (R\&D Systems) for $18 \mathrm{~h}$ in polystyrene 96-well culture plates. Based on previous work from our laboratory, we used submaximal, physiologic doses of TNF (1 ng/mL) and LPS (10 $\mathrm{ng} / \mathrm{mL}$ ) to stimulate the release of IL-8 and MIP (15).

We used a near-maximal inhibitory dose of IL-10, from the dose-response studies above, to assess NF- $\kappa \mathrm{B}$ activity (at 30 $\mathrm{min}$ ) and $\mathrm{I}-\kappa \mathrm{B} \alpha$ protein expression at $30 \mathrm{~min}$ and $3 \mathrm{~h}$ after stimulation of PMNs with LPS. These times were chosen on the basis of previous studies showing NF- $\kappa \mathrm{B}$ activation at 30 min (8). We also determined $\mathrm{I}-\kappa \mathrm{B} \alpha$ expression at $3 \mathrm{~h}$, because a recent study using neutrophils from adults indicated the effect of IL-10 on neutrophils may need a 3-h exposure (16).

\section{Measurements}

ELISA for IL-8 and MIP. Release of IL-8 and MIP from PMNs was measured in cell culture supernatants using commercially available ELISA kits (R\&D Systems) as previously described (3).

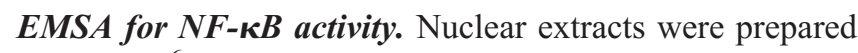
from $5 \times 10^{6}$ PMNs for EMSA as previously described (8, 9). The nuclear extracts were incubated $(20 \mathrm{~min}$ at room temperature) with 10 fmol of ${ }^{32} \mathrm{P}$-labeled NF- $\kappa \mathrm{B}$ oligonucleotide (5'-TTGTTACAAGGGGACTTTCCGCTGGGGACTTTCCAGGGAG-GC-3') in $20 \mu \mathrm{L}$ of binding buffer (20 mM Tris-Cl, pH 7.5, 150 mM KCl, 1 mM EDTA, $1 \mathrm{mM}$ DTT, $0.1 \%$ NP-40, 6\% glycerol) supplemented with $20 \mu \mathrm{g}$ of acetylated BSA and $2 \mu \mathrm{g}$ of poly-deoxyinosinedeoxycytosine. The resulting complexes were resolved on $5 \%$ nondenaturing polyacrylamide gels in $0.5 \times$ Tris-BorateEDTA buffer at $180 \mathrm{~V}$ for $2.5 \mathrm{~h}$. The gels were dried and exposed to autoradiographic film (Kodak Biomax MS; Kodak, Rochester, NY, U.S.A.) with intensifier screen at $-80^{\circ} \mathrm{C}$ overnight.

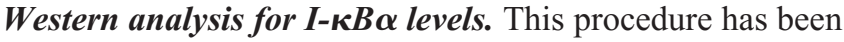
previously described in detail from our laboratory (8). Cytoplasmic extracts were prepared from PMNs stimulated with TNF or LPS in the presence or absence of IL-10, with separation of proteins on $12 \%$ SDS-PAGE, followed by transfer to a nitrocellulose membrane. The membranes were washed with Tris-buffered saline-Tween (20 mM Tris-Cl, pH 7.6, $1.37 \mathrm{mM}$ $\mathrm{NaCl}, 0.05 \%$ Tween 20), blocked in Tris-buffered salineTween containing 5\% nonfat dry milk (Tris-buffered salineTween-milk) for $2 \mathrm{~h}$, and incubated $1 \mathrm{~h}$ at $25^{\circ} \mathrm{C}$ with $\mathrm{I}-\kappa \mathrm{B} \alpha$ primary antibody (SC-371; Santa Cruz Biochemicals, Santa Cruz, CA, U.S.A.) diluted (1:200) in Tris-buffered salineTween-milk. After washing in Tris-buffered saline-Tween, the membranes were incubated $\left(1 \mathrm{~h}, 25^{\circ} \mathrm{C}\right)$ with anti-rabbit secondary antibody conjugated to horseradish peroxidase and developed using enhanced chemiluminescence detection (Amersham, Piscataway, NJ, U.S.A.). To confirm equal amounts of loaded proteins, the membranes were stripped and reprobed with actin antibody as described previously (8).

\section{Statistical Analyses}

Results are expressed as mean \pm SEM. Statistical analyses were performed using ANOVA and the Mann-Whitney $U$ test, with an overall significance level of 0.05 before Bonferroni correction for multiple comparisons (serial doses of IL-10).

\section{RESULTS}

Figures 1 and 2 demonstrate the effect of serial doses of IL-10 on the release of IL- 8 and MIP, respectively, from PMNs stimulated with TNF. There was a trend toward inhibition of chemokine release by IL-10, but the results were not statistically significant for 1,10 , and $100 \mathrm{ng} / \mathrm{mL}(p>0.05, n=4)$.

In contrast, Figures 3 and 4 demonstrate the effect of serial doses of IL-10 on the release of IL-8 and MIP, respectively, from PMNs stimulated with LPS. There was a statistically significant and marked inhibition of both IL-8 and MIP release with exposure to IL-10 starting at $1 \mathrm{ng} / \mathrm{mL}(p<0.01)$. Therefore IL-10 at a dose of $10 \mathrm{ng} / \mathrm{mL}$ was selected as a near-maximal dose for studying the effect of IL-10 on NF- $\kappa \mathrm{B}$ activity and $\mathrm{I}-\kappa \mathrm{B} \alpha$ levels in subsequent experiments.

Activation of NF- $\kappa \mathrm{B}$ was directly measured by EMSA and indirectly measured by Western blot analysis of $\mathrm{I}-\kappa \mathrm{B} \alpha$ levels at 


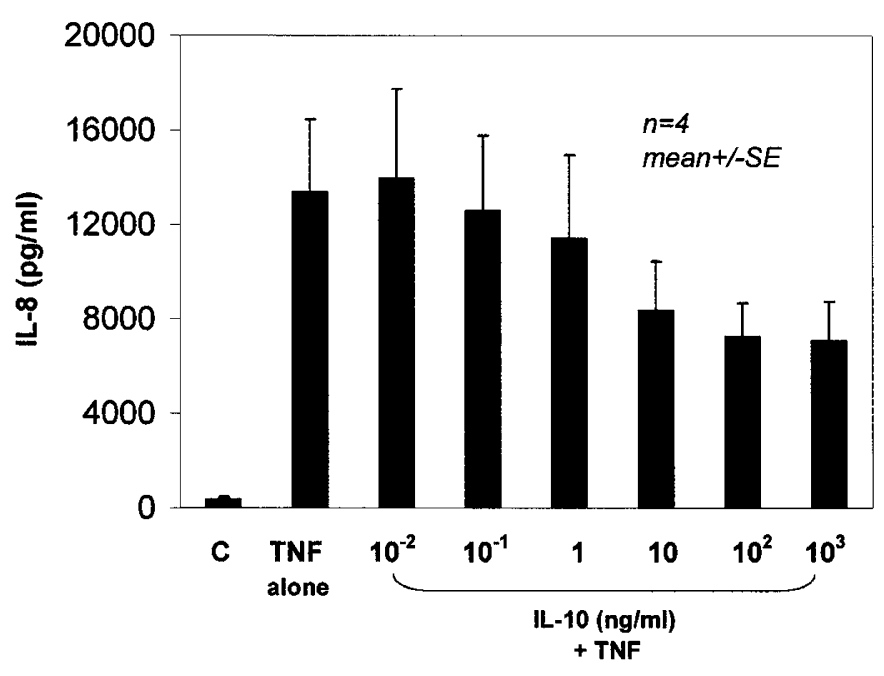

Figure 1. IL- 8 release by PMNs $\left(5 \times 10^{6} / \mathrm{mL}\right)$ of the newborn. IL- 8 was assayed from culture media after $18 \mathrm{~h}$ of stimulation with TNF $(1 \mathrm{ng} / \mathrm{mL})$ with and without a 1-h preexposure to serial doses of IL-10.

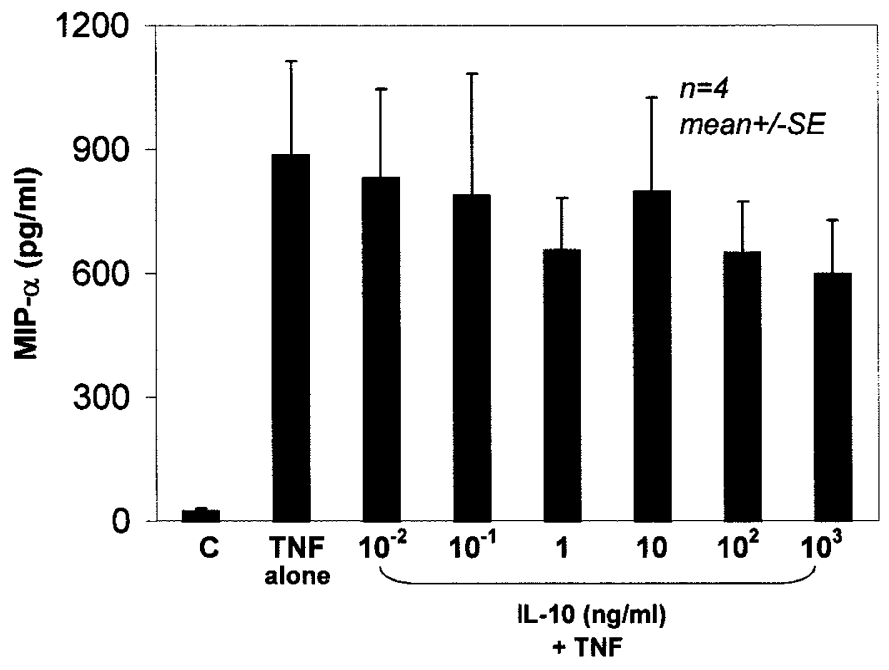

Figure 2. MIP release by PMNs $\left(5 \times 10^{6} / \mathrm{mL}\right)$ of the newborn. MIP was assayed from culture media after $18 \mathrm{~h}$ of stimulation with TNF $(1 \mathrm{ng} / \mathrm{mL})$ with and without a 1-h preexposure to serial doses of IL-10.

simultaneous times before and after stimulation of PMNs with LPS or TNF, and with and without exposure to IL-10 (10 $\mathrm{ng} / \mathrm{mL})$. Figure 5 demonstrates $\mathrm{I} \kappa-\mathrm{B} \alpha$ levels $($ top $)$ and NF- $\kappa \mathrm{B}$ DNA binding (bottom) in PMNs stimulated with TNF or LPS for $30 \mathrm{~min}$. The $\mathrm{p} 50 / 65$ and $\mathrm{p} 50 / 50$ subunits of NF- $\kappa \mathrm{B}$ are shown; the former heterodimer is the NF- $\kappa \mathrm{B}$ component responsible for the transcriptional up-regulation of proinflammatory mediators. Lane 1 demonstrates that before stimulation with LPS or TNF, there is abundant $\mathrm{I}-\kappa \mathrm{B} \alpha$ and no NF- $\kappa \mathrm{B}$ binding to its oligonucleotide in resting PMNs, indicating $\mathrm{NF}-\kappa \mathrm{B}$ is not activated. Submaximal doses of TNF or LPS, as shown in lanes 2 and 4 , resulted in a marked reduction in I- $\kappa \mathrm{B}$ levels, indicating degradation, and appearance of the NF- $\kappa \mathrm{B}$ p50/65 heterodimer indicating activation. Lanes 3 and 5 show that IL-10 had no effect on TNF- or LPS-induced stimulation of NF- $\kappa \mathrm{B}$ activity or I- $\kappa \mathrm{B} \alpha$ levels. In addition, IL-10 alone did not affect NF- $\kappa$ B activity in resting cells (lane 6). Figure 5 is a representation of three experiments.

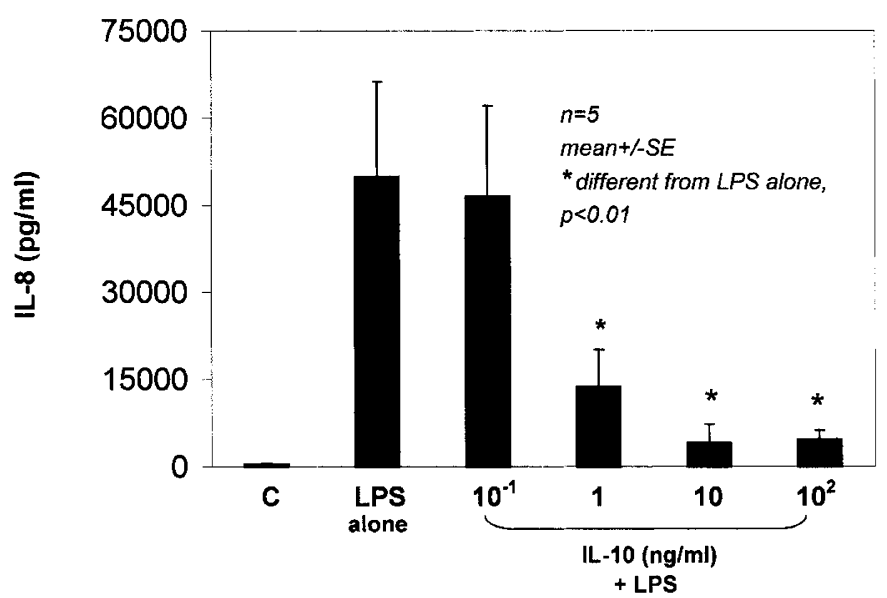

Figure 3. IL- 8 release by PMNs $\left(5 \times 10^{6} / \mathrm{mL}\right)$ of the newborn. IL- 8 was assayed from culture media after $18 \mathrm{~h}$ of stimulation with endotoxin (LPS, 10 $\mathrm{ng} / \mathrm{mL}$ ) with and without a 1-h preexposure to serial doses of IL-10.

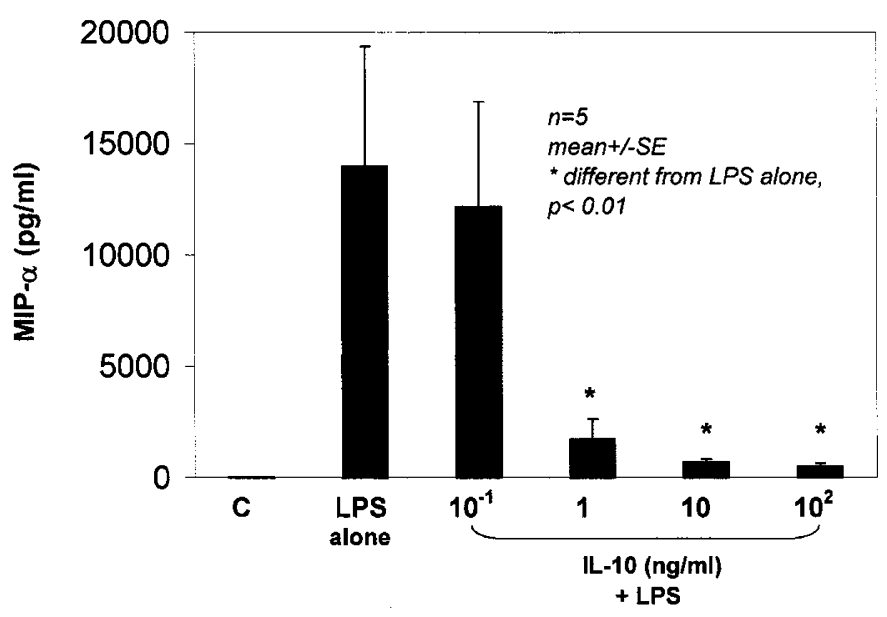

Figure 4. MIP release by PMNs $\left(5 \times 10^{6} / \mathrm{mL}\right)$ of the newborn. MIP was assayed from culture media after $18 \mathrm{~h}$ of stimulation with endotoxin (LPS, 10 $\mathrm{ng} / \mathrm{mL}$ ) with and without a 1-h preexposure to serial doses of IL-10.

$\begin{array}{lllllll}\text { TNF }(1 \mathrm{ng} / \mathrm{ml}) & - & + & + & - & - & - \\ \operatorname{LPS}(1 \mu \mathrm{g} / \mathrm{ml}) & - & - & - & + & + & - \\ \mathrm{IL}-10(10 \mathrm{ng} / \mathrm{ml}) & - & - & + & - & + & +\end{array}$

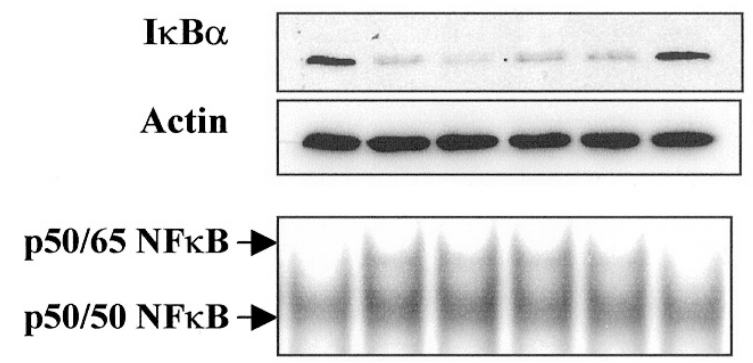

A

B

Figure 5. Effect of IL-10 on I- $\kappa \mathrm{B} \alpha$ degradation and NF- $\kappa \mathrm{B}$ activity in LPSand TNF-stimulated (for $30 \mathrm{~min}$ ) PMNs, isolated from the newborn, and preexposed to a dose of IL-10, which maximally inhibited chemokine release.

To determine whether IL-10 inhibition of chemokines was caused by a delayed inhibition of NF- $\kappa \mathrm{B}$, we examined I- $\kappa \mathrm{B} \alpha$ levels with two stimulating doses of LPS (10 ng and $100 \mathrm{ng}$ ) at $30 \mathrm{~min}$ (Fig. 6) and $3 \mathrm{~h}$ (Fig. 7). The results show that even at 


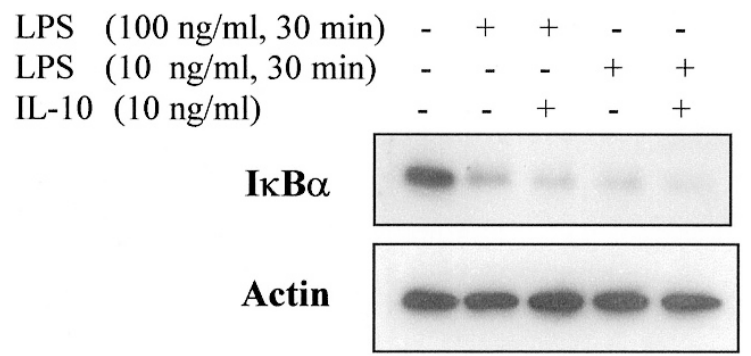

Figure 6. Effect of IL-10 on I- $\kappa \mathrm{B} \alpha$ degradation, $30 \mathrm{~min}$ after stimulation of PMNs, isolated from the newborn, with high and low doses of LPS. The dose of IL-10 used maximally inhibited chemokine release.

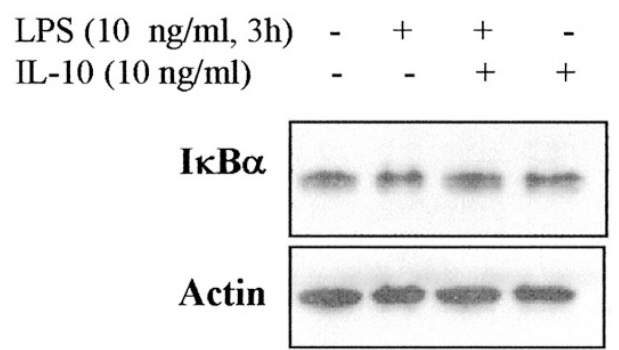

Figure 7. Effect of IL- 10 on I- $\kappa$ B $\alpha$ expression, $3 \mathrm{~h}$ after stimulation of PMNs, isolated form the newborn, with LPS. The dose of IL-10 used maximally inhibited chemokine release.

lower doses of LPS-induced PMN stimulation (10 and 100 $\mathrm{ng} / \mathrm{mL})$, IL-10 did not have any effect on I- $\kappa \mathrm{B} \alpha$ degradation after 30 min (Fig. 6). After $3 \mathrm{~h}$ of stimulation with LPS, I- $\kappa \mathrm{B} \alpha$ cytoplasmic levels were restored as a result of the NF- $\kappa \mathrm{B}-$ induced neosynthesis of I- $\kappa \mathrm{B} \alpha$ (Fig. 7). However, IL-10 again had no significant effect on the resynthesis of new I- $\kappa \mathrm{B} \alpha$. Figures 6 and 7 are representations of one of three experiments for each figure.

\section{DISCUSSION}

Antiinflammatory cytokine therapy may become a growing field of research in neonatal-perinatal medicine, because of our present lack of safe and effective therapy for diseases such as CLD (10). Neutrophil functions, long thought to be final effector processes in the acute inflammatory response, now are known to include self-amplifying proinflammatory functions, e.g. the release of chemokines (3). Our present study for the first time demonstrates the dose-related potency of IL-10 in the inhibition of neutrophil chemokine release when neutrophils of the newborn are stimulated by endotoxin. This inhibition did not occur to the same degree when they were stimulated by TNF; however, had a larger number of studies been performed, a partial inhibition by IL-10 may have been detectable. Because potential antiinflammatory therapy could be targeted against transcriptional activation of chemokines, we studied $\mathrm{NF}-\kappa \mathrm{B}$, a pivotal proinflammatory transcription factor (7) whose activity is associated with neutrophil chemokine release in the newborn (9). Surprisingly, IL-10 did not inhibit NF- $\kappa$ B activity in the neutrophil of the newborn under our experimental conditions.

Neutrophils are the first inflammatory cells to be recruited into the airways of newborns developing CLD $(1,2)$. The presence of chemokines such as IL-8 and MIP in the airway of infants with a high likelihood of developing CLD suggests that resident lung cells and neutrophils recruited into the lung initiate the acute inflammatory response $(5,6)$. There are now four classes of chemokines as defined by positioning of cysteine; IL-8 is part of the CXC chemokine class and MIP is part of the CC chemokine class. Accordingly, our experiments evaluated neutrophil release of two structurally different chemokines that have clinical relevance and are known to be potent stimulants of neutrophil chemotaxis in lung diseases of the newborn $(5,6)$.

In the present study we found that when neutrophils were stimulated with LPS, a nearly maximal inhibition of chemokine release was observed with IL-10 at a dose of $1 \mathrm{ng} / \mathrm{mL}$. Previous studies have examined IL-10 concentrations in bronchoalveolar lavage fluid from preterm infants ventilated for respiratory distress syndrome. In one study IL-10 was not detectable in the lungs of preterm infants (12). In a recent study, IL-10 concentrations rose in bronchoalveolar lavage from premature infants up to $5 \mathrm{~d}$ after birth; concentrations in the range of 0.1 to $1 \mathrm{ng} / \mathrm{mL}$ were detected (17). Both previous studies indicate that because of low levels of endogenous IL-10, for a short-lived period of time, premature infants with CLD may lack the antiinflammatory effect provided by IL-10.

Extrapolating our in vitro data suggests that supplementing with exogenous IL-10 to blood or alveolar levels in the $1-\mathrm{ng} / \mathrm{mL}$ range may hypothetically provide antiinflammatory protection to infants developing CLD. However, the following questions arise. First, do monocytes/macrophages or other airway cells of the newborn respond similarly to neutrophils with respect to IL-10 inhibition of chemokine release? And second, how important is TNF (18) as a stimulator of chemokine release in the airways of premature infants developing CLD? Although IL-10 did not inhibit TNF-induced chemokine release from neutrophils, our previous work demonstrated that dexamethasone did, at concentrations that are probably much lower than achieved when standard dexamethasone regimens are used clinically for the treatment of CLD (15). It is unknown whether IL-10 and dexamethasone have synergistic effects on chemokine release from cells that can release proinflammatory mediators.

There have been no previous studies in the newborn addressing the mechanism by which IL-10 suppresses proinflammatory chemokine release. During the last decade, increasing evidence has demonstrated that NF- $\kappa \mathrm{B}$ is a pivotal transcription factor associated with a variety of proinflammatory mediators and apoptosis pathways in a variety of cells (7). In the neutrophil, specifically, NF- $\kappa \mathrm{B}$ is bound to an inhibitory protein $(\mathrm{I}-\kappa \mathrm{B} \alpha)$ that is localized in the nucleus (8). I- $\kappa \mathrm{B} \alpha$ phosphorylation results in ubiquitination and rapid degradation of $\mathrm{I}-\kappa \mathrm{B} \alpha$ by the proteosome, leading to NF- $\kappa \mathrm{B}$ binding to DNA (7). In the present studies, we confirmed NF- $\kappa \mathrm{B}$ activation with I- $\kappa \mathrm{B} \alpha$ degradation when neutrophils were exposed to LPS or TNF; IL-10 had no effect on NF- $\kappa$ B activation, measured directly by EMSA or measured indirectly by Western blot analysis of $\mathrm{I}-\kappa \mathrm{B} \alpha$ degradation, up to $3 \mathrm{~h}$ after neutrophil stimulation. By $3 \mathrm{~h}$ after stimulation of neutrophils with LPS, I- $\kappa \mathrm{B} \alpha$ had been totally resynthesized. IL-10 had no effect on 
the resynthesis of I- $\kappa \mathrm{B} \alpha$. This indicates that IL-10 does not regulate NF- $\kappa \mathrm{B}$ signaling in neutrophils of the newborn.

The mechanisms of IL-10 inhibition of chemokine production by neutrophils need greater clarification. Studies involving neutrophils from adults indicate that gene transcription, mRNA destabilization, and de novo induction of a repressor protein may be involved (19-21). The transcriptional control of chemokine expression is complex and appears to involve multiple protein kinase cascades and several transcription factors such as NF- $\kappa \mathrm{B}$ and activating protein-1, as well as the formation of multiprotein complexes, which interact with DNA (21). Recent studies have shown that in human neutrophils from adults, IL-10 induces phosphorylation and activation of the transcription factor Stat 3, and up-regulates mRNA synthesis of the suppressor of cytokine signaling-3 (SOCS-3) $(16,22)$. Interestingly, however, the Stat 3 phosphorylation and SOCS-3 mRNA synthesis are more dependent on the expression levels of IL-10 receptor (IL-10R1), and more significantly enhanced after neutrophil stimulation with LPS for a few hours (16).

Whether there are developmental differences in IL-10 control of chemokine release, which explains why NF- $\kappa$ B activity was unaffected in our experiments, remains to be determined. Studies from our laboratory have demonstrated that there are developmental differences in IL-8 production (PMNs from newborns releasing IL-8 to a greater degree than PMNs from adults) and associated NF- $\kappa \mathrm{B}$ activity $(3,9)$. In addition, recent studies have shown maturational differences in the regulation of another transcription factor, activating protein-1 $(23,24)$, as well as in the expression of cell-surface receptors (25-27).

Endogenous IL-10 can act as a local, antiinflammatory cytokine, limiting inflammation as shown in animal experiments in which there is a disrupted IL-10 gene or administration of IL-10 antibody, leading to increased neutrophil recruitment, chemokine release, and worsening of disease $(28,29)$. Conversely, recombinant human IL-10, delivered s.c., has been shown to be safe and effective in patients with inflammatory disorders such as mild to moderately active Crohn's disease (13). Because there may be a relative deficiency of IL-10 in CLD, and because IL-10 is a potent inhibitor of chemokine release in the neutrophil of the newborn stimulated by LPS, we suggest that further work should be directed to the possibility of using exogenous IL-10 in the treatment of CLD. In addition, a better understanding of the underlying mechanisms accounting for antiinflammatory action of IL-10 may also lead to safer and more effective therapy for CLD compared with corticosteroids.

\section{REFERENCES}

1. Merritt TA, Cochrane CG, Holcomb K, Bohl B, Hallman M, Strayer D, Edwards III DK, Gluck L 1983 Elastase and alpha-1-proteinase inhibitor activity in tracheal aspirates during respiratory distress syndrome. J Clin Invest 72:656-666

2. Kwong KYC, Jones CA, Cayabyab R, Lecart C, Khuu N, Rhandhawa I, Hanley JM, Ramanthan R, deLemos RA, Minoo P 1998 The effects of IL-10 on pro-inflammatory cytokine expression (IL-1 $\beta$ and IL-8) in hyaline membrane disease (HMD). Clin Immunol Immunopathol 88:105-113
3. Zentay Z, Sharaf M, Qadir M, Drafta D, Davidson D 1999 Mechanism for dexamethasone inhibition of neutrophil migration upon exposure to lipopolysaccharide in vitro: role of neutrophil interleukin-8 release. Pediatr Res 46:406-410

4. Strieter RM, Kasahara K, Allen RM, Standiford TJ, Rolfe MW, Becker FS, Chensue SW, Kunkel SL 1992 Cytokine-induced neutrophil-derived interleukin-8. Am J Pathol 141:397-407

5. Munshi UK, Niu JO, Siddiq MM, Parton LA 1997 Elevation of interleukin-8 and interleukin-6 precedes the influx of neutrophils in tracheal aspirates from preterm infants who develop bronchopulmonary dysplasia. Pediatr Pulmonol 24:331-336

6. Murch SH, Costeloe K, Klein NJ, MacDonald TT 1996 Early production of macrophage inflammatory protein- $1 \alpha$ occurs in respiratory distress syndrome and is associated with poor outcome. Pediatr Res 40:490-497

7. Barnes PJ, Karin M 1997 Nuclear factor- $\kappa$ B - a pivotal transcription factor in chronic inflammatory diseases. N Engl J Med 336:1066-1071

8. Vancurova I, Miskolci V, Davidson D $2001 \mathrm{NF}-\kappa \mathrm{B}$ activation in TNF $\alpha$-stimulated neutrophils is mediated by protein kinase $\mathrm{C}$ delta: correlation to nuclear $\mathrm{I} \kappa \mathrm{B} \alpha$. J Biol Chem 276:19746-19752

9. Vancurova I, Bellani P, Davidson D 2001 Activation of nuclear factor-kappa B and its suppression by dexamethasone in polymorphonuclear leukocytes: newborn versus adult. Pediatr Res 49:257-262

10. Thebaud B, Lacaze-Masmonteil T, Watterberg K 2001 Postnatal glucocorticoids in very preterm infants: "the good, the bad, and the ugly?" Pediatrics 107:413-415

11. Cassatella MA 1998 The neutrophil: one of the cellular targets of interleukin-10. Int J Clin Lab Res 289:148-161

12. Jones CA, Cayabyab RG, Kwong KY, Stotts C, Wong B, Hamdan H, Minoo P, deLemos RA 1996 Undetectable interleukin (IL)-10 and persistent IL-8 expression early in hyaline membrane disease: a possible developmental basis for the predisposition to chronic lung inflammation in preterm newborns. Pediatr Res 39:966-975

13. Fedorak RN, Gangl A, Elson CO, Rutgeerts P, Schreiber S, Wild G, Hanauer SB, Kilian A, Cohard M, LeBeaut A, Feagan B 2000 Recombinant human interleukin 10 in the treatment of patients with mild to moderately active Crohn's disease. Gastroenterology 119:1473-1482

14. Tan ND, Davidson D 1995 Comparative differences and combined effects of interleukin-8, leukotriene $\mathrm{B}_{4}$, and platelet-activating factor on neutrophil chemotaxis of the newborn. Pediatr Res 38:11-16

15. Irakam A, Miskolci V, Vancurova I, Davidson D 2002 Dose-related inhibition of pro-inflammatory cytokine release from neutrophils of the newborn by dexamethasone, betamethasone, and hydrocortisone. Biol Neonate 82:89-95

16. Crepaldi L, Gasperini S, Lapinet JA, Calzetti F, Pinardi C, Liu Y, Zurawski S, de Waal Malefyt R, Moore KW, Cassatella MA 2001 Up-regulation of IL-10R1 expression is required to render human neutrophils fully responsive to IL-10. J Immunol 167:2312-2322

17. Beresford MW, Shaw, NJ 2002 Detectable IL-8 and IL-10 in bronchoalveolar lavage fluid from preterm infants ventilated for respiratory distress syndrome. Pediatr Res 52:973-978

18. Jonsson B, Tullus K, Brauner A, Lu Y, Noack G 1997 Early increase of TNF $\alpha$ and IL-6 in tracheobronchial aspirate fluid indicator of subsequent chronic lung disease in preterm infants. Arch Dis Child 77:F198-F201

19. Kasama T, Strieter RM, Lukacs NW, Burdick MD, Kunkel SL 1994 Regulation of neutrophil-derived chemokine expression by IL-10. J Immunol 152:3559-3569

20. Cassatella MA 1998 The neutrophil: one of the cellular targets of interleukin-10. Int J Clin Lab Res 28:148-161

21. Kracht M, Saklatvala J 2002 Transcriptional and post-transcriptional control of gene expression in inflammation. Cytokine 20:91-106

22. Cassatella MA, Gasperini S, Bovolenta C, Calzetti F, Vollebregt M, Scapini P, Marchi M, Suzuki R, Suzuki A, Yoshimura A 1999 Interleukin-10 (IL-10) selectively enhances CIS3/SOCS3 mRNA expression in human neutrophils: evidence for an IL-10-induced pathway that is independent of STAT protein activation. Blood 94:2880-2889

23. Yang G, Madan A, Dennery PA 2000 Maturational differences in hyperoxic AP-1 activation in rat lung. Am J Physiol Lung Cell Mol Physiol 278:L393-L398

24. Yang G, Shegog ML, Dennery PA 2002 Effect of glutathione on lung activator protein-1 activation and heme oxygenase- 1 induction in the immature rat. Pediatr Res $52: 34-39$

25. Lorant DE, Li W, Tabatabaei N, Garver MK, Albertine KH 1999 P-selectin expression by endothelial cells is decreased in neonatal rats and human premature infants. Blood 94:600-609

26. Gessler P, Neu S, Nebe T, Speer CP 1999 Granulocyte colony-stimulating factor receptor expression on neutrophils of term and preterm neonates with and without signs of infection. Eur J Pediatr 158:497-500

27. Bessler H, Komlos L, Punsky I, Ntambi JA, Bergman M, Straussberg R, Sirota L 2001 CD14 receptor expression and lipopolysaccharide-induced cytokine production in preterm and term neonates Biol Neonate 80:186-192

28. Yan XT, Zhuang M, Oakes J, Lausch RN 2001 Autocrine action of IL-10 suppresses pro-inflammatory mediators and inflammation in the HSV-1-infected cornea. J Leukoc Biol 69:149-157

29. Gerard C, Bruyns C, Marchant A, Abramowicz D, Vandenabeele P, Delvaux A, Fiers W, Goldman M, Velu T 1993 Interleukin-10 reduces the release of tumor necrosis factor and prevents lethality in experimental endotoxemia. J Exp Med 177:547-550 